\title{
EFFENTERRE, Henri van. Le Palais de Mallia et la Cité Minoenne. Etude de Synthèse. Rome, Ed. dell'Atheneo, 1980, 2 v. (s. Incunabula Graeca, 76).
}

\author{
Ālvaro $\mathrm{H}$. Allegrette
}

Universidade de São Paulo

Desde que as pesquisas foram iniciadas, na década de 20, pelos membros da École Française d'Athènes, o sítio de Mália tem-se revelado como uma das fontes mais ricas para o conhecimento da civilização minóica, o que pode ser atestado pela vasta gama de publicações a este respeito, destacando-se, no conjunto, os relatórios anuais dos trabalhos de EFA apresentados no Bulletin de Correspondance Hellénique e a série Etudes Crétoises, dedicada a Mália, que já abriga quase trinta títulos.

Neste contexto Henri van Effenterre aparece como um arqueólogo cujo nome está definitivamente associado a Mália, com o qual manteve uma estreita relação desde 1932, produzindo uma série de escritos sobre o sítio, dentre os quais apontamos o Guide des Fouilles Françaises en Crète, em colaboração com C. Tiré, além de três volumes dos Êtudes Crétoises. ${ }^{1}$

Com a publicação desta obra, o autor vem suprir uma lacuna que se tornava cada vez mais aparente nos estudos maliotas, a de um trabalho de síntese sobre Mália, que abarcasse a totalidade das informações provenientes das pesquisas neste sítio. Curiosamente, no mesmo ano é lançada uma obra de síntese sobre o palácio de Mália, a cargo de Olivier Pelon, dentro dos Êtudes Crétoises. ${ }^{2}$

\footnotetext{
EFFENTERRE, H. van. Mirabello - Nécropoles. Athènes, Paul Geuthner, 1948 (Etudes Crétoises, VIII).

EFFENTERRE, $\mathrm{H}$. van et alii. Site et Nécropoles (II). Athènes, Paul Geuthner, 1963 (Etudes Crétoises, XIII).

EFFENTERRE, H. van. Mallia, Centre Politique $I-L^{\prime}$ Agora. Athènes, Paul Geuthner, 1969 (totudes Crétoises, XVII).

PELON, O. Le Palais de Mallia V. Athènes, Paul Geuthner, 1980 (Etudes Crétoises, XXV).
} 
Le Palais de Mallia et la Cité Minoenne constitui um trabalho de peso para o leitor interessado em obter uma visão panorâmica e aprofundada deste sítio, apresentando em seus dois volumes, 634 páginas ao todo, 873 fotos, mapas, plantas e desenhos, 33 pranchas em cores, três índices remissivos e inúmeras notas de rodapé que permitem ao leitor o recurso a obras fundamentais para o estudo da civilização minóica.

Com uma preocupação maior do que a de executar uma pura descrição do palácio e da cidade de Mália, Effenterre organizou seu trabalho de maneira a abranger temas diversos e significativos para a compreensão do sítio, dividindo-o em quatro blocos com vinte e três capítulos que possibilitam uma observação e reflexão clara da dinâmica deste núcleo minóico, não elaborando no entanto uma história de Mália (p. 3).

O primeiro bloco, "Archéologues sur le terrein" (p. 3-94), inclui um primeiro capítulo dedicado à apresentação de um pequeno histórico das pesquisas em Mália, onde o autor destaca Fernand Chapouthier, cujo nome é central nas pesquisas em Mália, a quem considera seu pai espiritual (p. XI); segue-se uma discussão da cronologia do sítio, na qual ele ressalta as dificuldades advindas da ausência de correspondência entre as fases cerâmicas e as fases cronológicas no palácio (p. 43), de outro lado ele demonstra a necessidade de se acrescentar um novo periodo, o arqueopalacial, que abrange o intervalo no qual ocorre o delineamento de um núcleo palacial, por volta de 2000 a. C. (p. 33-36), tendo como respaldo um paralelo no palácio de Festos, conforme a investigação de D. Levi. ${ }^{3}$

Ao entrarmos no terceiro capítulo, lidamos com um conjunto de reflexões e críticas que devem ser levados em conta no exame deste sítio: as restaurações e sondagens complementares, que, mesmo justificáveis pelo estado das ruínas ou elucidação de questões relativas a certas áreas e níveis, interferem com a leitura dos vestígios ou se revelam inócuas (p. 45-58). Seria prematura uma discussão

3 LEVI, D. Festos e la Civiltà Minoica. Rome, Ed. dell'Atheneo, 1976 (s. Incunabula Graeca, 60). 
aqui sobre tais pontos, o que mereceria um trabalho à parte lidando especificamente com este aspecto da pesquisa no sítio, o que não é cabível aqui.

Fechando este bloco, há dois capítulo que tratam de dois temas relevantes à análise do sítio: um refere-se à caracterização física e geográfica da região de Mália, avaliando o potencial dos recursos para exploração econômica e as rotas de comunicação com Creta Oriental e Central. Para o autor o núcleo de Mália não teria uma atividade portuária, mantendo-se relativamente isolado daquelas áreas acessíveis por mar e mesmo por terra, possuindo autonomia para a sua existência (p. 75-79). Quanto à própria instalação deste núcleo, tema do capítulo seguinte, desenvolve sinteticamente como ocorrera a substituição progressiva de uma comunidade aldeã do periodo prépalacial por um núcleo urbano no arqueopalacial (c. 200 a. C.), evidenciada pela presença dos fragmentos cerâmicos que delimitam uma área que se estendia da quadra Gama até a parte Leste do palácio (p. 81-94).

O segundo bloco, intitulado "Au Temps des Premiers Palais" ( $p$. 97-281), detalha a ocupação do sítio no período protopalacial (c. 2000-1650 a. C.), partindo inicialmente de um extenso capítulo sobre os materiais e técnicas empregados na arquitetura minóica, no qual o autor releva justificadamente o valor do trabalho de J. Shaw, ${ }^{4}$ ainda um guia seguro neste campo de estudos. Dando a devida importância à concepção da estrutura arquitetônica da habitação maliota, Effenterre apresenta as transformações ocorridas nesta como um índice do próprio processo de desenvolvimento do núcleo urbano, sendo que as inovações perceptíveis na quadra $\mathrm{Mu}$ assinalariam uma regularização tanto da distribuição quanto da organização interna dessas habitações (p. 176-180).

Em seguida, ao abordar os grandes conjuntos arquitetônicos, ou seja, a "villa" Alfa, a quadra Mu, e o complexo cripta hipostila/ ágora, o autor levanta a hipćtese de uma espécie de "democracia primitiva" cujo centro estaria naquele complexo, local destinado à reunião de representantes da comunidade maliota e a cerimônias

4

SHAW, J. Minosn Architecture: Materials and Techniques, Annuario della Scuola di Atene, 49:7-259, 1973. 
públicas, enquanto que a quadra $\mathrm{Mu}$ concentraria as atividades administrativas e produtivas do núcleo urbano. $\overline{\mathrm{E}}$ a constituição de uma "nebulosa palacial", como foi denominada esta situação de coexistência das primeiras construções palaciais com tais complexos urbanos, sem que fosse possível definir claramente um poder palacial, mas antes um estado de equilíbrio político que só seria rompido no final do proto-palacial (p. 181-200). Tal hipótese tem sua crítica na discrepância cronológica que, segundo Poursat, não possibilitaria tal articulação desses complexos. ${ }^{5}$

As necrópoles são apresentadas em um capítulo à parte, o qual traz uma exposição extremamente cuidadosa e consistente da distribuição espacial e temporal destas, caracterizando-as de modo que se torna perceptível a existência de uma diferenciação social nas necrópoles, como ocorre em Chrysolakkos, considerada antes uma tumba real, porém Effenterre defende seu uso para uma nobreza maliota (p. 247). Complementando este capítulo há a caracterização dos costumes funerários minóicos, enfatizando a necessidade de uma investigação mais minuciosa dos ritos funerários (p. 248-252).

A partir do capítulo 11 intitulado "L'Urbanisme protopalatial à Mallia", o autor penetra no tema fundamental de seu trabalho, interpretando o plano de desenvolvimento urbano de Mália, demonstrando que o conjunto urbano, embora articulado ao palácio, não possui neste o seu ponto referencial (p. 278). Trata-se antes da existência de dois pólos de concentração humana, um fundado sobre a quadra $\mathrm{Mu}$ e o complexo cripta hipostila/ágora, outro sobre o palácio (p. 279-281).

Na parte III, "Le Palais dans la Ville" (p. 287-422), Effenterre nos introduz no período neopalacial (1650-135 a.C.) quando ocorre o apogeu da civilização minóica e o ponto máximo de expansão do núcleo da Mália. Inicialmente expondo aspectos técnicos da arquitetura palacial, com especial atenção aos diversos procedimentos de construção com aparelhos de calcáreo e ammouda e estruturas em madeira (particularmente notáveis na fachada Sul do Pátio

5

POURSAT,J.-Cl. La Ville Minoenne de Mallia: recherches et publications récentes. Révue Archéologique, p. 61-82, 1988. 
central), Effenterre executa uma análise indispensável das escadarias palaciais e das questões relativas ao número e distribuição dos andares superiores do edifício (p. 305-312).

Seguindo uma ordem coerente, segue-se uma descrição sistemática do palácio (p. 313-370), onde faremos uma ressalva à brevidade com que foi exposta a ala ocidental, não sendo percebida claramente a articulação das quadras componentes deste setor, com exceção das quadras VI e VII. Ao finalizar este capítulo com uma apreciação da situação do palácio dentro do núcleo urbano, o autor refuta uma similaridade entre a articulação cidade/palácio minóica e oriental, observando que na primeira a cidade e o palácio obedecem a planos organizacionais, mesmo que diferenciados e, no caso oriental, a cidade forma conjuntos desordenados que não apresentam qualquer plano organizacional (p. 371-378). Em relação à organização palacial, Effenterre põe em discussão dois pontos essenciais, a identidade do governante e as funções palaciais. A impossibilidade de definição deste governante como um reisacerdote ou grande sacerdote não impede que seja caracterizado como um indivíduo do sexo masculino com atributos religiosos, ligado a uma personagem feminina de caráter divino, possivelmente uma espécie de deusa-mãe (p. 379-281). Já ao analisar a natureza das funções palaciais, ele propõe que sejam consideradas as seguintes categorias, dentre as quais se observa um predomínio das três primeiras no espaço do palácio: aparato, recepção, reverência (religião?), administração, estocagem, produção artesanal e habitação (p. 383-390). Para Effenterre a soma destas funções permite que se delineie um Estado maliota que estaria a meio caminho de um totalitarismo à egípcia e um sistema fragmentário de poder (p. 390), o que levaria à caracterização de um Estado não muito forte ou estruturado (p. 392).

No capítulo sobre as "villas" neopalaciais é feita uma síntese do conjunto de transformações que estas estruturas sofreram, com a incorporação de novos elementos e a alteração de seu espaço interno, dentro de edificações mais regulares que as do período anterior, resultando em construções com menor complexidade e maior facilidade de circulação entre as suas unidades básicas: vestíbulo de entrada, polythyron, átrio, sala lustral, peças de serviço 
(incluindo cozinha, depósitos, latrinas, alojamentos) e oficinas (eventual). Tais caracteres são assinalados nas casas da quadra Delta (alfa, beta e gama), Dzeta (alfa, beta e gama), quadra E e a casa de Hágia Varvara (p. 393-422).

Será no quarto bloco deste trabalho que Effenterre porá em discussão a sociedade e a economia maliota. "Les Travaux et les Jours à Mallia" (p. 425-598) consiste na recuperação das informações sobre a atividade humana em Mália a partir da caracterização do "maliota médio", suas divindades e cultos, sua organização econômica, suas produções artesanais, seus artesãos e os sistemas de escrita e contabilidade. Este indivíduo, segundo o autor, se inseria dentro de uma sociedade de base agrária cerealista e arborícola, com uma residência situada em uma das quadras, provavelmente segundo seu ofício, mantendo estoques próprios de alimentos, tendo em sua casa o seu local de trabalho; qual era o seu status social e se existiriam escravos são duas questões cujas respostas ainda não estão acessíveis pela ausência de maiores elementos (p. 427-431).

Ao falar sobre as divindades maliotas o autor entra em um terreno no qual as evidências são raras, com exceção de duas estatuetas humanas e um cântaro com representações incisas de figuras humanas, que ele sugere formarem uma tríade de divindades (p. 434). Maior sorte houve quanto à identificação dos acessórios de culto (ritãos, machados bipenes, taças e pratos de oferendas e estatuetas de animais) e na localização e caracterização dos santuários urbanos e domésticos, que apresentam material similar. No caso do palácio há espaços destinados a atividades religiosas, porém para Effenterre cabe o questionamento da finalidade da "loggia", da sala colunada, da sala lustral e mesmo do "kernos" e do "bothros" (p. 448-451); como as lareiras, estes dois últimos elementos não apresentam evidências suficientes para indicar uma função religiosa (p. 180) .

Fixando a atenção sobre a questão econômica (p. 453-468), Effenterre faz uma leitura do sistema econômico maliota com base na presença de um excedente de produção, de um tributo e da capacidade de estocagem das habitações e do palácio, elaborando uma hipótese centrada em um modelo no qual ocorresse a suces- 
são de duas formas distintas. Em linhas gerais, inicialmente haveria uma autonomia das grandes residências em relação ao palácio, que receberiam tributos dos produtores, os quais por sua vez permaneceriam com o excedente da produção; posteriormente o palácio passa a centralizar a captação dos tributos, repassando às grandes residências uma parcela deste, por estarem então em dependência hierárquica administrativa do palácio. Esta hipótese se enquadra com o processo de concentração do poder político no palácio que assinala a transição do período protopalacial para o neopalacial. Neste esquema o comércio exterior se daria a partir do palácio, que utiliza parte do tributo como mercadoria de troca ao lado dos bens manufaturados (p. 465-467).

Para aquele leitor interessado na produção artesanal e no artesão, os três capítulos seguintes constituem um material de grande valia, tendo o autor dispendido cuidado particular na elaboração de um painel detalhado das atividades e indivíduos enquadrados nestas categorias. Em um primeiro instante o autor lida com os fabricantes de vasos de pedra, artigos de bronze, marfins e jóias, executando uma análise dos procedimentos técnicos, classes de artefatos e os padrões estilísticos (p. 469-504). À parte são estudados os oleiros e a cerâmica, sendo que Effenterre efetua uma critica pertinente às pesquisas sobre a cerâmica maliota, assinalando a ausência quase total de trabalhos que ampliem o conhecimento neste campo, seja quanto à análise das argilas ou uma tipologia das formas dos vasos, apesar do volume considerável de material (p. 505). Após este comentário segue-se um pequeno guia para a cerâmica de Mália, expondo as técnicas de fabricação (p. 506-509); uma tipologia cerâmica com base no volume das produções e uma investigação das continuidades e rupturas no desenvolvimento da produção maliota a partir de quatro categorias: lamparinas, cântaros, taças e vasos de argila verde. Como fecho, são analisadas as relações exteriores conforme os indícios de produções cerâmicas maliotas em outras regiões da ilha e do Mediterrâneo. Um tratamento similar é dado no capítulo sobre a glíptica, onde o autor define a morfologia dos selos, os motivos e a natureza dos suportes das impressões, destacando o material encontrado na oficina de selos do MM IIB próxima da quadra $\mathrm{Mu}$, que esclareceram em 
grande parte o processo de fabricação dos selos, as técnicas, instrumentos e materiais empregados (p. 551-561).

De autoria de Louis Godart é o capítulo sobre a escrita e a contabilidade em Mália, no qual ele executa um balanço dos documentos existentes, relacionando as áreas de ocorrência de material hieroglífico e em Linear $\mathrm{A}$, os suportes, o conteúdo, a escrita e a língua (no caso do Linear A), demonstrando que não há sinais de haver uma correspondência entre ambos os sistemas quanto à língua (p. 598), salientando o uso diferenciado de cada sistema como instrumentos contábeis.

O capítulo final constitui um texto curto e reflexivo sobre o declínio do núcleo minóico, no qual o autor defende uma causa de natureza geográfica, a sua própria situação física que não favorecera a instalação de um porto, limitando a região à atividade agrícola, impossibilitando assim que Mália acompanhasse o processo de desenvolvimento das atividades marítimas egéias (p. 599), o que levou ao seu abandono progressivo entre o fim do séc. XV a. C. e o séc. XIV a. C., ocorrendo posteriormente a instalação de uma população micênica.

Le Palais de Mallia et la Cité Minoenne oferece ao leitor, tanto ao especialista quanto ao iniciante, a oportunidade de obter uma vasta cobertura deste sítio minóico, fornecendo-lhe o instrumental necessário para analisar, interpretar, criticar e questionar o conjunto de informações e hipóteses suscitadas nestes sessenta anos de atividade quase ininterrupta dos pesquisadores da EFA. Como complemento precioso ao trabalho, o autor acrescenta um índice topográfico que possibilita a identificação e localização de qualquer estrutura existente no sítio, formando com o volume Plans et Indices da série Études Crétoises o conjunto essencial de referências para o estudo do palácio e a cidade de Mália.

Uma ressalva que deve ser feita é quanto à diagramação dos volumes, pois as ilustrações, ao mesmo tempo em que auxiliam na compreensão do texto, terminam por fragmentá-lo em excesso.

Apesar disto, este trabalho certamente se encontra dentro de qualquer bibliografia que trate da civilização minóica ou das culturas da Idade do Bronze egéia, pois o leitor terá à sua disposição uma obra que efetuou uma síntese clara e lógica das principais características de Mália, um dos três principais sítios da Creta minóica. 